\title{
Improvements in Cognition and Educational Attainment as a Result of Integrating Music into Science Teaching in Elementary School
} Raed Mualem, ${ }^{1,2,3^{*}}$ Belal Badarne, ${ }^{1,4,5}$ Seema Biswas ${ }^{1,6}$ Maha Hnout, ${ }^{1}$ Sherif Ganem, ${ }^{1,5}$ Yusra Zbedat, ${ }^{3}$ Evleen Shehadeh, ${ }^{1}$ Igor Waksman, ${ }^{6}$ and Calixto Machado ${ }^{7}$

\author{
${ }^{1}$ The Institute for Brain and Rehabilitation Sciences, Israel. \\ ${ }^{2}$ Oranim Academic College of Educatin, Israel. \\ ${ }^{3}$ Ramat Zevulun High School, Ibtin, Galilee, Israel. \\ ${ }^{4}$ Kaye Academic College of Education, Israel. \\ ${ }^{5}$ Sakhnin College for Teacher Education. \\ ${ }^{6}$ Global Health Research Laboratory, Department of Surgery B, Galilee Medical Center, Nahariya, Israel. \\ ${ }^{7}$ Institute of Neurology and Neurosurgery, Havana, Cuba.
}

*Corresponding Author: Raed Mualem, The Institute for Brain and Rehabilitation Sciences, Israel.

Received date: February 23, 2021 ; Accepted date: April 23, 2021; Published date: April 29, 2021

Citation: Raed Mualem, Belal Badarne, Seema Biswas, Maha Hnout, Sherif Ganem, et al. (2021) Improvements in Cognition and Educational Attainment as a Result of Integrating Music into Science Teaching in Elementary School. J. Neuroscience and Neurological Surgery. 8(5);

DOI:10.31579/2578-8868/161

Copyright: ( 2021 Raed Mualem, This is an open-access article distributed under the terms of The Creative Commons Attribution License, which permits unrestricted use, distribution, and reproduction in any medium, provided the original author and source are credited.

\begin{abstract}
:
BACKGROUND AND OBJECTIVE: This study examines the effect on third-grade students' academic achievement and their pleasure and interest in lessons as a result of the incorporation of music into science classes.

MATERIAL AND METHODS: Sixty third grade Arab school children were studied before and after listening to a Mozart Concerto. Their pleasure and interest in the lesson were evaluated using the 20-statement Barak questionnaire. Comparison was made between an initial 6 lessons without music and subsequent 6 lessons with music.

In another study at the Institute of Neurology and Neurosurgery in Havana, Cuba, continuous electroencephalographic monitoring (CEEG) was performed in 15 third-grade school children during 10 minutes at basal conditions and for 10 minutes while listening to the same piece of music.

RESULTS: Assessment scores in the science examination were significantly higher overall after listening to music. A clear increment of alpha and gamma absolute powers was found when listening to music, although for the alpha band this augmentation was significantly greater. An increment of the alpha band power was related to significantly better performance of spatial-temporal tasks when listening to music. Changes in the gamma frequency band represent cognitive processes. Hence, CEEG analysis adds to evidence that listening to music can increase enjoyment and improve academic achievement among elementary school students. CONCLUSION: We propose that music stimulates the formation of neural networks that prime the brain for learning. We recommend that teachers of core subjects, especially mathematics, science and languages, begin their lessons with 5 minutes of calm music.

Keywords: music education; science education; educational achievement; cognition; EEG
\end{abstract}

\section{INTRODUCTION}

1. The effect of music on human development

The positive impact of music on human cognitive development, including fetal development, has been extensively studied [1]. The first three years of life are the most crucial in brain development [1-7]. A child's interaction with his or her environment determines the level of development of brain architecture $[4,8]$ as neurons multiply rapidly from the moment of birth, creating neural networks important for the rest of life [2,3,6-8]. Neurons not exposed to stimuli are less likely to connect - music is an important stimulus for the growth of functional neural networks throughout the brain [1-7]. The effect on brain development remains significant in school age children and is, therefore, of considerable interest in improving learning conditions in children's formative years, especially in the classroom. An empirical study measuring differences in spatial intelligence showed an improvement of $43 \%$ in students learning to play the piano versus $11 \%$ in students studying computer science [3]. Music also impacts intellectual development, in particular the ability to listen and absorb language [7]. Listening to Mozart has been found to significantly help mothers cope with stress and improve their temperament $[1-3,6,7]$ which in turn, may positively impact the environment at home for children, Music also encourages calm and good quality sleep $[1,3,8]$. Some researchers argue that intellectual improvement 
is only in the short term, and that if music does have an effect on a child's intelligence, the effect would be later - in the teenage years $[1,6,8]$.

\subsection{How music affects the brain}

The main argument of most studies dealing with the effect of music on brain development [9-13] is that there are two important characteristics common to both language and music: both are used for communication; and, both have syntax with rules that dictate the correct combination of different components (the characters and words) [13, 15-17 ]. The findings of the various visualizations performed on the human brain indicate the existence of an area in the frontal lobe that allows the construction of syntax in music and language, while other parts of the brain address aspects related to verbal and musical processing [8]. When an individual listens to music, other areas located outside the auditory cortex are usually involved in thinking processes $[6,9,10,15,17]$. The visual, tactile and emotional experiences that an individual experiences earlier in life affect the specific location in which the human brain processes music [7,13,15-17]. When a musician plays an instrument, activity occurs in other areas such as the motor cortex and regions involved in planning and performing certain precisely timed movements. [17]. In 1998, Pentev showed that when musicians listen to piano playing, about $25 \%$ of their auditory cortical regions in the left hemisphere are highly activated $[18,19]$. This phenomenon is unique to music and does not occur with other sounds $[7,15,17]$. The researchers found that the expansion of the activated area was greater if the subject began to study music from a very young age. Studies in children suggest that musical experience at an early age promotes their cognitive development [7,9,10,13,15-17]. In 2004, an experiment was conducted in Canada among children aged four and five, in which brain responses were recorded while listening to tunes of the piano, violin and to pure tones. The findings of the study showed that children who were more exposed to music in their homes, showed stronger auditory brain activity compared to children aged approximately three years who were not exposed to music. The response to sounds among musicians is stronger in part because their auditory cortex is larger. There is a relationship between the percentage increase in the volume of the auditory cortex and the level of musical training. This implies that learning music increases the number of neurons and neural networks that process music. $[18,19]$

\subsection{Cognitive processes in classroom learning}

Effective teaching strategies focus on how information is presented in the classroom and how, children receive, organize and commit this information to memory, Classroom teaching efforts focus on increasing motivation, pleasure and attention in the classroom, and facilitating the process of building associations and connections children make between pieces of information [20-21]. Repetition and application of what is learned during class are two strategies in enhancing memory and understanding. Problemsolving skills further augment recall and understanding while promoting reasoning and executive functions such as decision-making [21-22].

In education psychology these teaching and learning strategies may be described in terms of four cognitive steps: attention, encoding information, storage (memory), and retrieval of information. Music may enhance any or all of these processes [22-23].

One possible mechanism rests on Stanovich's tripartite model of the mind the interplay of the reflective, algorithmic and autonomous (intuitive) mind which may describe the connectivity of the frontal and prefrontal areas with the limbic system. [24-29] The effect of music on the limbic system causes relaxation while priming the reflective (rational/reasoning) and algorithmic minds for learning [5-10]. In terms of Bloom's taxonomy [30], (Figure. 1), priming or creating favourable conditions for learning may assist focus and concentration that enhances the acquisition of facts (knowledge), stimulates neuronal activity toward memory and recall, analysis and understanding, and algorithmic thinking essential to the application of knowledge and higher order cognitive executive functions such as decision making [31]. Thus, cognition and neuronal pathways are implicated in measurable educational competencies and CEEG brain activity while listening to music would be expected to show increased alpha waves brought on by relaxing music and increased gamma wave activity during enhanced problem-solving and concentration as learning occurs in the classroom.

Bloom's Taxonomy

Produce new or original work

Justify a stand or decision

Draw connections among ideas

Use information in new situations

Explain ideas or concepts

Understand

Remember

Figure 1: Bloom's Taxonomy [31]

\subsection{Study objective}


The aim of this research was to investigate the effect of music on learning by testing three aspects of cognition: (1) pleasure and interest (attention) (2) recall and retrieval of information (3) brain activity while listening to music.

\section{MATERIAL AND METHODS}

This research is presented in two parts:

Israel: (1) pleasure and interest (attention) and (2) recall and retrieval of information were assessed in the classroom in an elementary school in Israel

Cuba: (3) brain activity after listening to music was investigated using CEEG in school children in Cuba.

\subsection{Israel:}

\section{Participants}

Research was conducted among 60 elementary school children - 24 female and 36 male - in grade 3 (aged 8 to 9 years) in Galilee. All participants were from middle class backgrounds as defined by Hollingshead and Redlich criteria [32]. IRB approval was obtained from the Research Committee of Oranim Academic College.

\subsection{Procedure}

Research was conducted in class during the teaching of the Science and Technology course: Materials and their Properties. The course comprised twelve 30-minute lessons, which proceeded as follows: The first five lessons were taught without music. Assessment was conducted during the sixth lesson (also without music). The next five lessons were conducted after participants listened to a piece of music. The twelfth lesson comprised assessment preceded by the same piece of music.

\section{Music:}

The piece of music used from the seventh to twelfth lesson was Mozart's concerto for Flute and Harp Concerto in C major, K.299/297c also known as Mozart's Relaxing Concerto for studying or Classical Study Music for Reading and Concentration played on YouTube for five minutes before each lesson

(https://www.youtube.com/watch?v=vwIUJbIU57s\&feature=youtu.be). Exactly the same excerpt of music was played for all six lessons to participants seated at their desks. The lesson began immediately after the music stopped.

\section{Lesson delivery:}

Lessons were conducted in Arabic by a single teacher in the format used for all Science and Technology teaching at the school.

\section{Assessment:}

On the sixth (without music) and twelfth (with music) lessons participants completed a questionnaire on (1) pleasure and interest (attention) (2) took a science examination on the topic of 'Materials and their Properties' that assessed overall academic performance (A) knowledge and recall, (B) understanding and application and (C) evaluation and synthesis

Motivation and pleasure were assessed using a 20-statement-Likert-scalequestionnaire (Appendix No. 1) devised by Barak [33] translated into Arabic.
Academic performance was examined using the national grade 3 written examination developed by the National Center for Science Teaching at Tel Aviv University (www.matar.ac.il) and the Ministry of Education in Israel translated into Arabic by a lecturer of the Department of Science at Oranim College (a local teacher-training college). The examination comprises open and closed questions on 'Materials and their Properties' and tested educational competencies of (A) knowledge and recall, (B) understanding and application and $(\mathrm{C})$ evaluation and synthesis.

\subsection{Statistical analysis}

Paired t-test comparisons were performed with and without music as each participant served as his or her own control. Non-parametric Spearman's rho correlations were performed in order to examine the impact of pleasure and interest on exam performance.

\subsection{Cuba}

Brain activity after listening to music was investigated using continuous EEG. CEEG is a rapidly evolving technology. Because the brain undergoes continuous and dynamic changes, CEEG was considered to be an effective method for real-time monitoring of functional brain changes after listening to music.

\section{Participants}

Fifteen school children in the third grade (aged 8 to 9) of "Gonzalo de Quezada" Havana School underwent CEEG analysis with IRB approval of the Institute of Neurology and Neurosurgery, Havana, Cuba.

\section{Procedure}

\section{CEEG analysis}

Participants were studied in our laboratory under conditions of controlled temperature (from 24 to $26^{\circ}$ Celsius), noise attenuation and dimmed lights. CEEG was recorded from 19 standard locations over the scalp according to the 10-20 system: Fp1, Fp2, F3, F4, F7, F8, T3, T4, C3, C4, P3, P4, T5, T6, $\mathrm{O} 1, \mathrm{O} 2, \mathrm{Fz}, \mathrm{Cz}$, and Pz.

After careful cleansing of the skin, disc EEG tin electrodes were fixed using a conductor paste and connected to the input box of the digital Continuous EEG Monitoring system (Neuronic, S.A.). Monopolar leads were recorded using linked ears as a reference. Technical parameters for EEG were: gain 20,000; pass-band filters $0.1-70 \mathrm{~Hz}$; "notch" filter at $60 \mathrm{~Hz}$; noise level of 2 $\mu \mathrm{V}$ (root mean squared); sampling frequency $200 \mathrm{~Hz}$; and electrode-skin impedance never higher than $5 \mathrm{~K} \Omega$. For monitoring purposes, a 7 bipolar chest electrocardiogram (ECG) lead was simultaneously recorded with 0.5 to $30 \mathrm{~Hz}$ EEG filters. CEEG was recorded for 5 minutes without music (basal conditions) and during 5 minutes after listening to the YouTube recoding of Mozart's concerto for Flute and Harp Concerto in C major, K.299/297c (https://www.youtube.com/watch?v=vwIUJbIU57s\&feature=youtu.be) in all 15 children.

\section{RESULTS}

\subsection{Effects of Music on Educational Achievement}

To test the effect of music on examination performance, a t-test was performed for dependent samples as shown in Table 1 below:

\begin{tabular}{|l|l|l|l|l|}
\hline & Without music N=60 & With music $\mathbf{N}=\mathbf{6 0}$ & & \\
\hline Aspects of Cognition & Average \pm SD & Average \pm SD & \% Change & t-test \\
\hline
\end{tabular}




\begin{tabular}{|l|l|l|l|l|}
\hline Knowledge and recall & $69.0 \pm 8.81$ & $89.23 \pm 6.23$ & $29.3 \%$ & $12.25 * * *$ \\
\hline Understanding and application & $65.22 \pm 8.49$ & $85.63 \pm 7.42$ & $31 \%$ & $13.32 * * *$ \\
\hline Evaluation and synthesis & $60.23 \underline{+6.20}$ & $80.80 \pm 7.10$ & $34 \%$ & $16.70 * * *$ \\
\hline Overall score & $64.81 \underline{7} 7.44$ & $85.22 \pm 6.46$ & $31.5 \%$ & $15.25 * * *$ \\
\hline
\end{tabular}

$* * * p<0.001$

Table 1: T-test for dependent samples to examine the differences between aspects of cognition and academic performance with and without music Scale from 0-100.

Overall mean examination scores (out of a total of 100) for all 60 participants were $(64.81 \pm 7.44)$ without music and $85.22 \pm 6.46$ after listening to music an improvement of $31.5 \%$. (significance $15.25, \mathrm{p}<0.001$ ).

Out of 100 (A) knowledge and recall scores without music were 69.0+-8.81 and with music $89.23 \pm 6.23$, an increase of $29.3 \%$ (significance $t-12.25$, $\mathrm{p}<0.001)$. In (B) understanding and application scores without music were $65.22 \pm 8.49$ and with music $85.63+\_7.42$, an increase of $31 \%$ significance

(t 13.32, $\mathrm{p}<0.001)$. In (C) evaluation and synthesis scores without music were $60.23 \pm 6.2$ and with music $80.8+-7.10$, an increase of $34 \%$ (significance $16.7, \mathrm{p}<0.001)$.

A strong correlation (Table 2) was found between examination scores of students who listened to music in A, B and C: the strongest between A, B and $C(r=0.82, p<0.001)$, then between $A$ and $B(r=0.76, p<0.001)$; and finally between $\mathrm{B}$ and $\mathrm{C}(\mathrm{r}=0.68, \mathrm{p}<0.001)$.

\begin{tabular}{|l|c|c|c|}
\hline Aspects of cognition & Knowledge and recall & Understanding and application & Evaluation and synthesis \\
\hline Knowledge and recall & $1 * * *$ & $0.82^{* * *}$ & $0.76^{* * *}$ \\
\hline $\begin{array}{l}\text { Understanding and } \\
\text { application }\end{array}$ & $0.82^{* * *}$ & $1 * * *$ & $0.68^{* * *}$ \\
\hline Evaluation and synthesis & $0.76^{* * *}$ & $0.68^{* * *}$ & $1 * * *$ \\
\hline
\end{tabular}

$* * * p<0.001$

Table 2: Pearson correlations between aspects of cognition

\subsection{Effects of music on pleasure and interest}

The effect of music on pleasure and interest was evaluated using a t-test for dependent samples as shown in Table 3 below:

\begin{tabular}{|l|l|l|l|l|}
\hline & Without music N=60 & With music N=60 & & \\
\hline Variable & Average + SD & Average + SD & \% of Change & t-test \\
\hline Interest and enjoyment & $2.20+0.77$ & $4.17 \pm 0.62$ & $89.5 \%$ & $14.57 * * *$ \\
\hline$* * * p<0.001$
\end{tabular}

Table 3: T-test for dependent samples to examine the differences between students' pleasure and interest (attention) in lessons with music and without music Scale from 1-5

Out of a total score of 5 , pleasure and interest in lessons that incorporated music were $4.17 \pm 0.62$ versus $2.20 \pm 0.77$, an increase of $89.5 \%$ (significance 14.57, $\mathrm{p}<0.001)$.

\subsection{Effect of attention on learning}

Using Pearson's correlation, in lessons that incorporated music a strong correlation was found between pleasure and interest scores and examination scores $(\mathrm{r}=0.77, \mathrm{p}<0.001)$. There is also a significant positive relationship ( $\mathrm{r}$ $=0.69, \mathrm{p}<0.001)$ between pleasure and interest and A, pleasure and interest and $\mathrm{B}(\mathrm{r}=0.70, \mathrm{p}<0.001)$ and pleasure and interest and $\mathrm{C}(\mathrm{r}=0.71, \mathrm{p}<0.001)$ (Table 4).

\begin{tabular}{|l|l|}
\hline Aspects of cognition & Interest and enjoyment \\
\hline Knowledge and recall & $0.69 * * *$ \\
\hline $\begin{array}{l}\text { Understanding and } \\
\text { application }\end{array}$ & $0.70 * * *$ \\
\hline Evaluation and synthesis & $0.71 * * *$ \\
\hline
\end{tabular}

Table 4: Pearson correlation to examine the relationship between pleasure and interest (attention) and aspects of cognition

\subsection{CEEG analysis}

In Figures 2, 3, and 4, we show representative subjects. There was a clear and statistically significant increment of the alpha absolute power comparing basal conditions and listening to music. Gamma absolute power also showed a significant incremental increase when listening music, but less than alpha absolute power. 


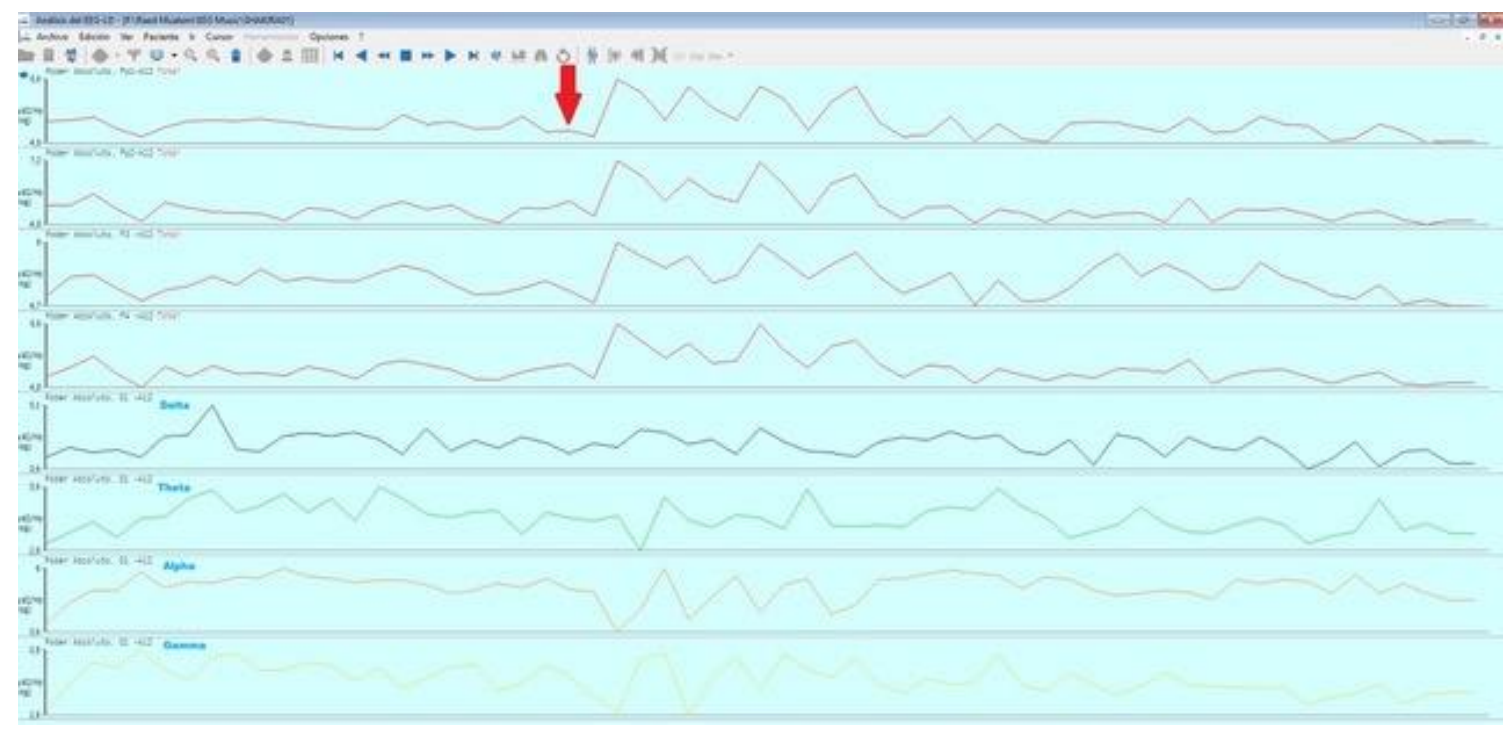

Figure 2: Incremental increase of alpha and gamma absolute powers when listening the music. Red arrow indicates the moment the subject began to listen to music.

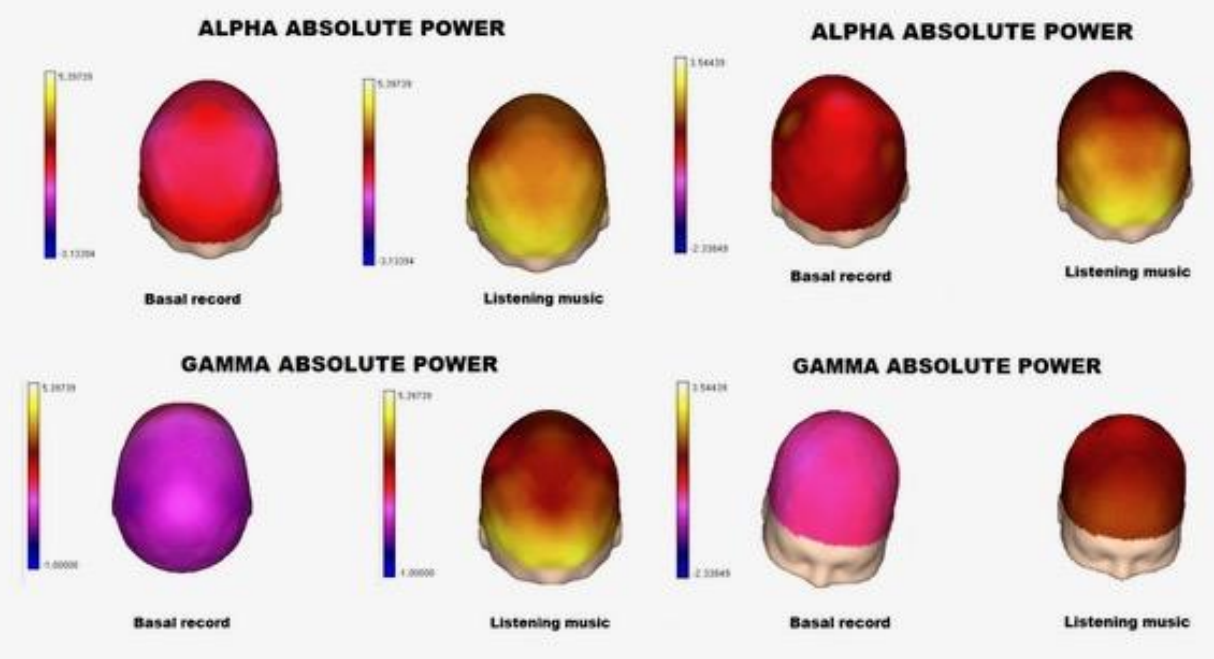

Figure 3: Comparing basal conditions and listening to music - incremental increase in both alpha and gamma absolute powers, although alpha band augmentation was greater.

\section{DISCUSSION AND CONCLUSIONS}

Listening to music for 5 minutes before each lesson and the examination resulted in a statistically significant improvement in examination performance overall and in specific educational competencies. Pleasure and interest (attention) were significantly improved by listening to music and affected overall academic performance as well as improving individual learning competencies - levels of cognition.

We propose a mechanism by which this improvement in cognition may have been achieved: CEEG analysis comparing basal conditions versus listening to music demonstrated incremental increases in the alpha and gamma bands, consistent with findings reported by Jausovec's et al [34]. Regarding the gamma activity, oscillatory neural activity in the gamma frequency range
(30-90 Hz) has been shown to accompany a wide variety of cognitive processes. Gamma-band activity and the synchronization of neural activity in the gamma-frequency range have been observed in different cortical and subcortical structures and have been associated with different cognitive functions. The results of EEG analysis in this research supports evidence that listening to music increases pleasure and interest (stimulation of the limbic pathway) which in turn primes the frontal and prefrontal areas for improved learning and cognition through stimulation of connecting neural networks. Music appears to stimulate all processes of cognition in learning - promoting the acquisition of basic knowledge, and its understanding, analysis and application.

There is neurochemical evidence to support these findings. Music increases the secretion of the neurotransmitter dopamine, which raises the level of 
pleasure and willingness to concentrate and learn. Dopamine is one of the neurotransmitters in the human brain that is also linked to serotonin. Dopamine is significantly involved in facilitating high cognitive functions, and, hence, also related to managerial/executive functions [35]. These findings are consistent with the reports of Crancic, Wilson, and Prior [36] that teaching music significantly improves spatio-temporal thinking skills. The findings of studies reviewed by Portowitz and Klein [37] indicate the existence of a significant positive relationship between music education and student academic achievement and social adaptation. However, few studies have examined how this process actually takes place. This research seeks to shed light on a possible mechanism of enhanced cognition through music priming of the cortico-limbic loop. If this mechanism is shown in further research to be the likely explanation, the implications for enhancing learning in the classroom are substantial. Music is a relatively inexpensive and accessible means of simulating learning among children. More research is needed to examine whether all music is equally effective, how long beneficial effects last and to what extent long term recall is enhanced by music. Portowitz and colleagues [38] reported the practice and evaluation of a musical education model called "Harmony," which uses new technologies and contemporary theories to improve learning. The findings of their study indicated that music has the ability to improve students' managerial functions, especially working memory, self-regulation and cognitive flexibility.

Fernandez [39] emphasized that music evokes movement and is a central and important force for the physical and mental development of the individual whose response to singing and music is mainly characterized by enjoyment derived directly from listening to music as a therapeutic tool.

\section{Limitations and further research}

There is clearly a need to replicate these results across language, mathematics and the teaching of all science topics in school children. While the effect of this particular Mozart piece is well documented, we want to know the effects of playing music for more than 5-minutes, playing music in the background during lessons, investigating the effects of other music (there are differences in what is perceived to be calming and what may be a distraction). While participants served as their own controls for the purposes of this research, we would like to know more about the confounding or additive effects of nutrition, sleep, exercise, mental health and, of course, the level of difficulty of the subjects learned during lessons. Assessment during or at the end of every lesson may elucidate the effect of music on learning versus performance in examinations - cognitive activity and related educational competencies would need to be carefully scrutinised, so that the most can be made of every learning opportunity, and both formative and summative assessment optimized.

Ideally, brain activity during lessons would be studied directly. There are obvious difficulties of simultaneous CEEG analysis in significant numbers of participants, and of performing this while lessons are in progress. Thus, for now, CEEG research and studies of cognition while learning in the classroom must be researched as separate entities.

In conclusion, we have shown the significant effect of music on learning in the classroom through improved academic performance. We have shown that music increases pleasure and interest (attention) in the lesson, and that improved attention significantly impacts learning and cognition at all levels.

Source(s) of support: None

Acknowledgement-Financial support and sponsorship: Nil
Conflicts of Interest of each author/ contributor: see attached file no' 3Conflicts of Interest. There are no conflicts of interest

\section{References}

1. Alexander, R. (2010). Children, their world, their education. Final report and recommendations of the Cambridge Primary Review.

2. Jacobsen, S. L. (2012). Music therapy assessment and development of parental competences in families where children have experienced emotional neglect: An investigation of the reliability and validity of the tool, Assessment of Parenting Competencies (APC) (Doctoral dissertation, Aalborg University, The Faculty of Humanities, Institute for Language and Culture)

3. Koops, L. H. (2011). Perceptions of current and desired involvement in early childhood music instruction. Visions of Research in Music Education, 17(1), 1-22.

4. Leisman, G., Mualem, R., \& Mughrabi, S. K. (2015). The neurological development of the child with the educational enrichment in mind. Psicología Educativa, 21(2), 79-96.

5. Schellenberg, E. G., \& Weiss, M. W. (2013). Music and cognitive abilities.

6. Schurig, M., Busch, V., \& Straub, J. (2012). Effects of structural and personal variables on children's development of music preference. In Conference Proceedings of the 12th International Conference of Music Perception and Cognition and the 8th Conference of the European Society for the Cognitive Sciences of Music (pp. 896-902).

7. Tierney, A., \& Kraus, N. (2013). Music training for the development of reading skills. Progress in brain research, 207, 209-241.

8. World Health Organization. (2012). Care for child development: improving the care of young children. World Health Organization

9. Agres, K., Bigo, L., Herremans, D., \& Conklin, D. (2016, June). The Effect of Repetitive Structure on Enjoyment in Uplifting Trance Music. In Proceedings of the 14th International Conference for Music Perception and Cognition (ICMPC)(San Francisco, CA) (pp. 280-282)

10. Erkkilä, J. (2016). The Future of Music Therapy for Persons with Depression Jaakko

11. Murrock, C. J. (2016). Concept analysis: Music therapy. Research and theory for nursing practice, 30(1), 44.

12. Pereira, C. (2016). Hypothermia induced reversible state of unconsciousness/insentience in snails (Achatina fulica) and the therapeutic effect of a meditative chant on this state. International Journal of Fauna and Biological Studies. 2016b, 3(1), 97-104.

13. Perlovsky, L. "Cognitive function of music and meaningmaking." J. Biomusic Eng. S 1 (2016).

14. Stober, S., Prätzlich, T., \& Müller, M. (2016). Brain Beats: Tempo Extraction from EEG Data. In ISMIR (pp. 276-282).

15. Mualem, R., Leisman, G., Zbedat, Y., Ganem, S., Mualem, O., Amaria, M., \& Ornai, A. (2018). The effect of Movement on cognitive Performance. Frontiers in public health, 6, 100.

16. Noble, T. (2004). Integrating the revised Bloom's taxonomy with multiple intelligences: A planning tool for curriculum differentiation. Teachers College Record, 193-211.

17. Portowitz, A., \& Klein, P. S. (2007). MISC-MUSIC: a music program to enhance cognitive processing among children with learning difficulties. International Journal of Music Education, 25(3), 259-271.

18. Weinberger, N. M. (2004). Music and the brain. Scientific American, 291(5), 88-95.

19. Hyde, K. L., Lerch, J., Norton, A., Forgeard, M., Winner, E., Evans, A. C., \& Schlaug, G. (2009). Musical training shapes 
structural brain development. Journal of Neuroscience, 29(10), 3019-3025.

20. Ahmed, W., \& Mudrey, R. R. (2019). The role of motivational factors in predicting STEM career aspirations. International Journal of School \& Educational Psychology, 7(3), 201-214.

21. Lamb, R., Akmal, T., \& Petrie, K. (2015). Development of a cognition-priming model describing learning in a STEM classroom. Journal of Research in Science Teaching, 52(3), 410437.

22. Degrave, P. (2019). Music in the Foreign Language Classroom: How and Why?.Journal of Language Teaching and Research, 10(3), 412-420.

23. YILMAZ, Y. Y., \& Sihhiye, A. T. (2011). The mozart effect in the foreign language classroom a study on the effect of music in learning vocabulary in a foreign language. International Journal on New Trends in Education and Their Implications, 2(3), 88-98.

24. Ejersbo, L. R., Leron, U., \& Arcavi, A. (2014). Bridging intuitive and analytical thinking: Four looks at the 2-glass puzzle. For the Learning of Mathematics, 34(3), 2-7.

25. Kahneman, D. (2002). Maps of bounded rationality: A perspective on intuitive judgment and choice. Nobel prize lecture, 8, 351-401.

26. Kahneman, D., \& Klein, G. (2009). Conditions for intuitive expertise: a failure to disagree. American psychologist, 64(6), 515.

27. Leron, U., \& Hazzan, O. (2006). The rationality debate: Application of cognitive psychology to mathematics education. Educational Studies in Mathematics, 62(2), 105-126.

28. Stanovich, K. E., \& West, R. F. (2000). Individual differences in reasoning: Implications for the rationality debate?. Behavioral and brain sciences, 23(5), 645-665

29. Stanovich, K. (2011). Rationality and the reflective mind. Oxford University Press.

\section{Appendices}

\section{Appendix 1:}

In the questionnaire (translated from the questionnaire developed by Barak [33] there are 20 statements about pleasure and interest in studying science and technology.

Please check the most appropriate response:

\begin{tabular}{|l|c|c|c|c|c|}
\hline & $\begin{array}{l}\text { Agree } \\
\text { strongly }\end{array}$ & Agree & $\begin{array}{l}\text { Agree } \\
\text { partially }\end{array}$ & Disagree & $\begin{array}{l}\text { Disagree } \\
\text { strongly }\end{array}$ \\
\hline $\begin{array}{l}\text { 1. I think that science is a very interesting } \\
\text { subject. }\end{array}$ & $\square$ & $\square$ & $\square$ \\
\hline $\begin{array}{l}\text { 2. In science lessons I get answers to questions } \\
\text { that intrigue me }\end{array}$ & $\square$ & $\square$ & $\square$ & $\square$ \\
\hline $\begin{array}{l}\text { 3. In science lessons I can express my own ideas. } \\
\text { 4. I can succeed in learning science even without } \\
\text { the teacher's help. }\end{array}$ & $\square$ & $\square$ & $\square$ & $\square$ \\
\hline $\begin{array}{l}\text { 5. Science shouldn't be an obligatory lesson in } \\
\text { school. }\end{array}$ & $\square$ & $\square$ & $\square$ & $\square$ \\
\hline \\
6. The number of hours per week for science
\end{tabular}

30. Bloom, B. S., Engelhart, M. D., Furst, F. J., Hill, W. H., \& Krathwohl, D. R. (1956). Taxonomy of Educational Bbjectives: Cognitive Domain. New York: McKay.

31. Vanderbilt, (2016) Blooms Taxonomy. https://cft.vanderbilt.edu/guides-sub-pages/blooms-taxonomy/

32. Hollingshead, A. B., \& Redlich, F. C. (1958). Social class and mental illness: Community study.

33. Barak, M., Watted, A., \& Haick, H. (2020). Establishing the validity and reliability of a modified tool for assessing innovative thinking of engineering students. Assessment \& Evaluation in Higher Education, 45(2), 212-223.

34. Jaušovec, N., Jaušovec, K., \& Gerlič, I. (2006). The influence of Mozart's music on brain activity in the process of learning. Clinical neurophysiology, 117(12), 2703-2714.

35. Madden, G. J., \& Bickel, W. K. (2010). Impulsivity: The behavioral and neurological science of discounting. American Psychological Association.

36. Črnčec, R., Wilson, S. J., \& Prior, M. (2006). The cognitive and academic benefits of music to children: Facts and fiction. Educational Psychology, 26(4), 579-594.

37. Portowitz, A., \& Klein, P. S. (2007). MISC-MUSIC: a music program to enhance cognitive processing among children with learning difficulties. International Journal of Music Education, 25(3), 259-271.

38. Portowitz, A., Peppler, K. A., \& Downton, M. (2014). In Harmony: A technology-based music education model to enhance musical understanding and general learning skills. International Journal of Music Education, 32(2), 242-260.

39. Fernandez, S. (2018). Music and brain development. Pediatric annals, 47(8), e306-e308. 


\begin{tabular}{|l|c|c|c|c|c|}
\hline lessons should be increased. & & & & & \\
\hline 7. Science lessons fascinate me. & $\square$ & $\square$ & $\square$ & $\square$ & $\square$ \\
\hline 8. Science lessons bore me. & $\square$ & $\square$ & $\square$ & $\square$ & $\square$ \\
\hline $\begin{array}{l}\text { 9. It is important for me to understand the topics } \\
\text { taught in science lessons. }\end{array}$ & $\square$ & $\square$ & $\square$ & $\square$ & $\square$ \\
\hline 10. Science lessons are easy for me to study. & $\square$ & $\square$ & $\square$ & $\square$ & $\square$ \\
\hline $\begin{array}{l}\text { 11. I enjoy learning science. } \\
\text { 12. In the future I would like to be a scientist. }\end{array}$ & $\square$ & $\square$ & $\square$ & $\square$ & $\square$ \\
\hline $\begin{array}{l}\text { 13. Science studies enable me to understand } \\
\text { daily phenomena. }\end{array}$ & $\square$ & $\square$ & $\square$ & $\square$ & $\square$ \\
\hline $\begin{array}{l}\text { 14. I have confidence in my ability to succeed in } \\
\text { my science studies. }\end{array}$ & $\square$ & $\square$ & $\square$ & $\square$ & $\square$ \\
\hline $\begin{array}{l}\text { 15. I help others in science lessons. } \\
\text { 16. I read articles and watch TV broadcasts that } \\
\text { present science topics. }\end{array}$ & $\square$ & $\square$ & $\square$ & $\square$ & $\square$ \\
\hline $\begin{array}{l}\text { 17. I am very interested in explanations of } \\
\text { scientific phenomena. }\end{array}$ & $\square$ & $\square$ & $\square$ & $\square$ & $\square$ \\
\hline $\begin{array}{l}\text { 18. I think that understanding science is } \\
\text { important to everyone. }\end{array}$ & $\square$ & $\square$ & $\square$ & $\square$ & $\square$ \\
\hline $\begin{array}{l}\text { 19. It is difficult for me to learn science. } \\
\text { 20. Science has no connection to my life. }\end{array}$ & $\square$ & $\square$ & $\square$ & $\square$ & $\square$ \\
\hline
\end{tabular}

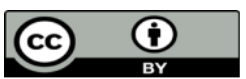

This work is licensed under Creative Commons Attribution 4.0 License

\section{To Submit Your Article Click Here: Submit Manuscript}

DOI:10.31579/2578-8868/161
Ready to submit your research? Choose Auctores and benefit from:

* fast, convenient online submission

* rigorous peer review by experienced research in your field

* rapid publication on acceptance

* authors retain copyrights

* unique DOI for all articles

* immediate, unrestricted online access

At Auctores, research is always in progress.

Learn more www.auctoresonline.org/journals/neuroscience-andneurological-surgery 